\title{
Interviewing Participants About Past Events: The Helpful Role of Pre-Interview Activities
}

\author{
Julia Ellis, Afshan Amjad, and Jun Deng
}

\section{University of Alberta}

\begin{abstract}
This article presents the work of two researchers who explored the use of pre-interview activities to support participants in recollecting and recording past events prior to an interview. Preinterview activities took the form of drawings, diagrams, or lists. Using such activities helped participants to recall events that had transpired over many years and facilitated comfortable, conversational interviews with enhanced opportunities for the researchers to focus on and respond to the stories shared by participants. One researcher was investigating the experience of culturally and linguistically diverse students in schools and the other was researching intercultural communication for international Chinese students at university.
\end{abstract}

Keywords: interpretive inquiry; hermeneutics; fusion of horizons 


\section{Interviewing Participants About Past Events: The Helpful Role of Pre-Interview Activities}

In qualitative studies, researchers often wish to learn about the past experiences of participants and can find it challenging to do so in ways that also support other desirable qualities or outcomes for interviews. In this paper we discuss the use of pre-interview activities that can facilitate participants' recall and reflection regarding past events. The use of this approach is examined in accounts of interviews by two researchers. Their accounts illustrate multiple benefits of the pre-interview activities both for learning about participants' past experiences and for other dynamics or qualities of the interviews.

Traditionally, since the development of interviewing strategies in ethnography, interviewers have primarily used grand tour questions, open-ended questions, and closed-ended questions (Brenner, 2006, pp. 358-359; Fetterman, 2010, pp. 43-44). Participants' drawings have been promoted for use in interviews with children, as will be discussed in the following section. Our purpose in this paper is to highlight the helpfulness of having participants complete drawings, diagrams, or special lists prior to the commencement of an interview when the researcher is interested in learning about the participant's past experiences with the topic of the research. The object in such interpretive inquiry is not to produce a life history narrative, but to learn about a sufficient number of pertinent past experiences to allow for identification of patterns, key dynamics, themes, or insights that can inform helpful action for these participants or others encountering similar experiences. In interpretive inquiry or in research in the constructivist paradigm, the researcher's goal is to develop a more informed and sophisticated interpretation (Guba \& Lincoln, 1994) and a transformed understanding of the problem that can enable the researcher and others to imagine ideas for helpful action ( Packer \& Addison, 1989).

\section{Pre-interview activities}

Doctoral students in a qualitative research course were introduced to the practice of using preinterview activities (Ellis, 2006) and were invited to conduct interviews that used such activities together with prepared, open-ended questions. Pre-interview activities can take many forms such as drawings, diagrams, various lists, timelines, or schedules that participants complete prior to the interview. Participants are offered several activities from which to choose. The expectation is that the interview will begin with the participant's presentation and discussion of the completed pre-interview activity. The following are examples of pre-interview activities:

- If someone were to make a movie about your experience of the topic of interest, make a list of key segments or scenes that ought to be included.

- Make a poster showing your ideas about the topic of interest (use drawings or pictures and words cut out from magazines).

- Draw two pictures: one of a good day and the other of a bad day in the activity of interest. (Ellis, 2006, p. 122)

Many authors such as Chandler and Johnson, Cummings, Malchiodi, Silver, Stone and Lemanek (cited in Ellis, 2006) have written about the value and process of having children make drawings that serve as the focus of talk in interviews. Ellis (2006) noted the following potential benefits of using children's drawings in interviews:

- Researchers can learn a great deal about the children's experiences and contexts without exhausting them with decontextualized questions. 
- The drawings can express personality, emotions, or perspectives that are difficult for the child to verbalize and awareness of these can enable the researcher to understand the child's words and stories differently.

- The drawings provide a concrete referent for language and can, thereby, help the child and the researcher to find shared meaning for the language they use together.

- Interacting with a child about his drawing provides a natural and comprehensible way to express genuine interest in what the child has to say and the quality of the interview relationship will depend upon the child's perception of the researcher's genuine interest in him or her.

- When an adult is interviewing a child, extra sensitivity about power relationships is required....The pre-interview activities-particularly when a selection of them are offered for the child to choose from-provide space for a child to choose what to share, how, and when.

- When asking for a collection of significant events or when specifically asking for examples of negative experiences, giving people time to reflect on which stories they will choose to share is a thoughtful way to proceed. (pp. 118-120)

Ellis (2006) presented a rationale for the use of pre-interview activities and suggested different kinds of sample pre-interview activities for diverse interview purposes such as general getting-to-know-the-participant interviews, learning about the context of interest, providing the opportunity for the participant to recall and select memories to share, and inviting participants to express the meaning of an experience metaphorically. In sections of the qualitative research course instructed over a number of years, graduate students have been using pre-interview activities with both children and adults. (For an example of the use of pre-interview activities with children in a Master's thesis see Sawler, 2005.)

Class participants in the qualitative research course also complete pre-interview activities as part of the getting-to-know-each-other tasks on the first day. After doing so, a common observation by students has been that once one starts drawing the diagrams or pictures, the drawings seem to take on a life of their own as "something takes over," that one follows rather than leads. Course participants have typically been surprised by the richness of ideas, information, and relationships that found their way into their drawings and diagrams.

\section{Hermeneutics, Interpretive Inquiry, and Interviewing}

Using pre-interview activities can be a helpful practice when a researcher's conception of interviews is informed by understandings or ideas from philosophical hermeneutics. In writing about hermeneutics and interpretive inquiry, Packer and Addison (1989a, p. 278) and Smith (2002, p. 190) have discussed the importance of approaching an entity in a way that enables it to show itself as opposed to fully determining one's data gathering methods in advance of an encounter with a participant. If research participants are offered a variety of different preinterview activities to choose from, it is more likely that one of them will serve as an inviting space for 1) the participant to make note of salient ideas or experiences that pertain to the topic of interest, and 2) the participant's preferred mode of expression of ideas or experiences.

Ellis (1998) studied the work of graduate students who undertook interpretive inquiry following ideas elaborated by Packer and Addison (1989a; 1989b). Packer and Addison emphasized the importance of entering the hermeneutic circle in the right way, with openness, 
humility, good will, and concerned engagement as opposed to simply seeking to prove a predetermined idea. With the inquiry process understood as a series of loops in a spiral, and with each loop representing a separate inquiry activity, Ellis (1998) noted that when the graduate student-researchers did not encounter any "uncoverings” (p. 22) or surprises in the first loop, they could find themselves spinning their wheels in terms of identifying a focus or purpose for the next loop or inquiry activity. On the other hand, Ellis observed that a wide range of openended activities worked well as the first inquiry activity to help the researchers understand both their participants and the research questions or problems differently. Thereafter, she encouraged qualitative research course students to offer their participants open-ended, pre-interview activities in the form of self-expressive drawings, diagrams, or lists. Packer and Addison (1989b) have explained that in interpretive inquiry "the first phase is that of entering the hermeneutic circle in the right way: discovering an appropriate workable perspective from which interpretation can proceed” (p. 3). The pre-interview activities can help to ensure that initial interactions with participants make productive contributions to the perspectives needed for conducting the inquiry.

Researchers conducting interpretive inquiry aspire to a fusion of horizons with participants, or in other words, endeavour to access or grasp participants' perspectives or points of view (Packer \& Addison, 1989a). Such a grasping of a participant's perspective should enable a researcher to discern how the participant's thoughts, feelings, and actions can be seen to be reasonable and coherent. Understanding a participant's perspective and experience should also enhance the researcher's sense of human solidarity with the participant (Smith, 1991). Using preinterview activities can support participants in recalling related experiences and telling stories about these at an interview. If drawings are made these might also express emotions or perspectives graphically. In as much as pre-interview activities may enhance participants' opportunities to present or express their experiences and reflections in interviews, so too might the researchers' fusion of horizons with the participants be achieved.

Amjad and Deng provide the following two accounts, which report what happened when they used pre-interview activities in their interviews. Both wished to have participants recall and share experiences that had occurred over a number of years. Their accounts illustrate the effectiveness of pre-interview activities in both supporting participants' recollections and facilitating other positive qualities for the interviews.

\section{The Experience of Students Who Immigrate to Canada}

Afshan Amjad, a doctoral student in the Department of Elementary Education at the University of Alberta, has an on-going research program concerned with the issues related to culturally and linguistically diverse (CLD) students' experience in schools. Afshan and her family migrated to Canada from Pakistan in 2005 when her children were 9 and 12 years of age. In her account below, Afshan writes about her interview with one of her daughters, a secondary school student, about her experience in school in Canada.

In an effort to develop a better understanding of the issues for CLD students, I (Afshan) interviewed one of my own daughters to learn her experiences in classrooms since we came to Canada. I chose to interview one of my own daughters because trust and a comfortable relationship are important in interviews and there was only going to be a single interview. I know my daughter very well and we have a strong relationship of trust. My daughter, who 
selected the pseudonym, Meena, is a very active Grade 12 student with a strong personal vision of the world around her. Thus, I expected that she would have much to share in the interview.

Prior to the interview, I gave Meena a list of pre-interview activities and asked her to choose and complete one that would give her the best opportunity to represent her school experience after immigrating to Canada. I adapted these activities from Ellis (2006). The pre-interview activities I offered were:

- Draw two pictures to show how changes happened in your school life after immigrating to Canada;

- Use four colours to make a drawing that represents your experience at school after immigrating to Canada;

- Draw a time line and mark on it the dates and titles of particular special events for you at school before and after immigrating to Canada;

- Draw a diagram and label it to show the happy times or events for you at your school after immigration; and,

- Draw a schedule of your school day or week before and after you immigrated to Canada.

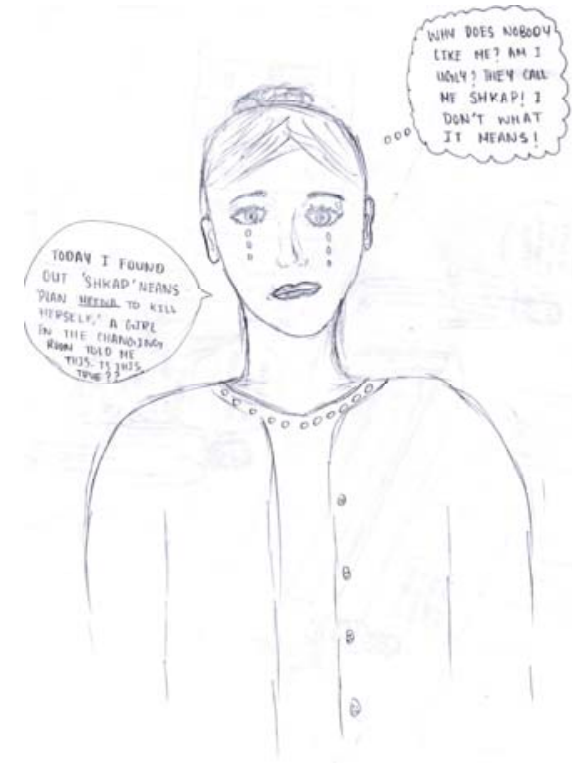

Figure 1. 


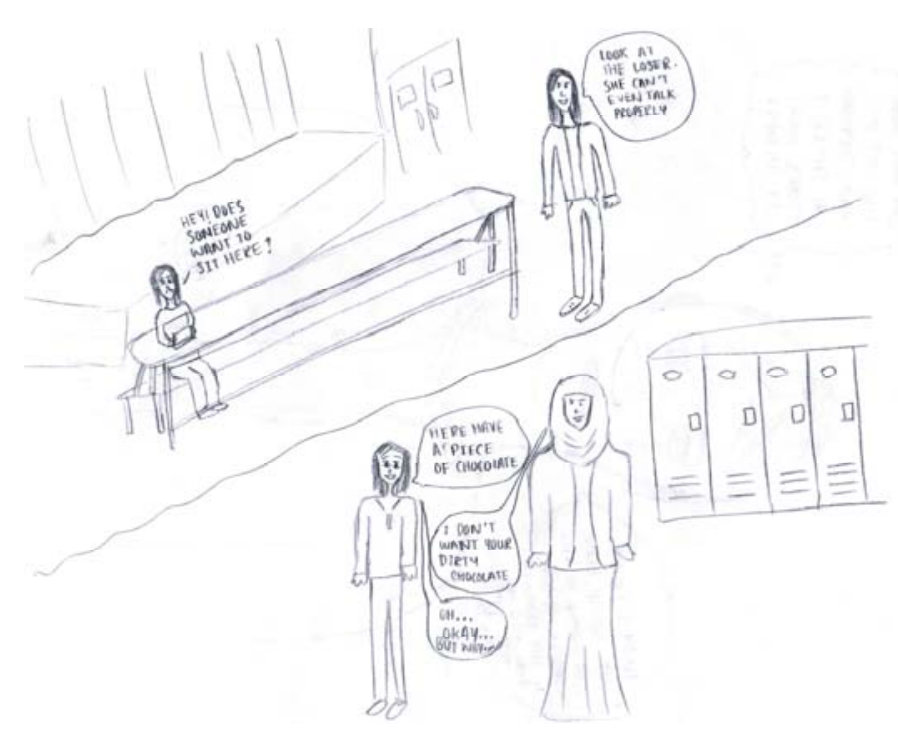

Figure 2.

Meena is very good at art and chose a drawing activity, "Draw two pictures to show how changes happened in your school life after immigrating to Canada." She gave me the drawing two days after my request. The two parts of the completed drawing are shown in Figure 1 and Figure 2. To begin our interview, I invited Meena to talk to me about her drawing. We completed the interview in Urdu and Meena assisted me with the translation of the transcripts. Making the drawing had clearly helped Meena to start thinking about her classroom experiences after moving to Canada. Sitting together with the drawing in front of us, Meena took the initiative in sharing her feelings and experiences with me as she talked about each of the elements in the drawing. The drawing included a large number of small images that represented memories of experiences. I have known my daughter since her birth but when she explained her drawing to me it seemed like I was just starting to know her. The pre-interview activity became a bridge between her recollections and reflections and my understanding.

As part of my analyses of the transcripts I identified key points or ideas that were expressed in the stories Meena shared about the past and the present as she spoke about her drawing. These key points are briefly categorized and summarized in Tables $\underline{1}$ and $\underline{2}$. The following quotations show examples of how Meena expressed her ideas and perspectives. Regarding her social life when she was first in Canada, she recalled: "I was also very sociable and made friends fast back home but here I felt somewhat isolated” (A. Amjad, interview, Nov. 14, 2010). Reflecting on her current experience and how things have changed, she stated:

Now I am not ashamed of my identity anymore because now I started thinking in other way. I now think that nobody else has a right to comment on what I am and how I look like. It is my personal matter. Now I am able to answer back to the other kids on their comments. I am no more ashamed of my accent. My teacher also noticed my good qualities that how respectful and cooperative I am as compare to my other class fellows and their views got changed as well. Canadian schools gave me confidence to speak and confidence in myself, which I lack when I came here and maybe that's why others were getting a chance to criticize me. I am not bothered by their comments any more. I am what I am I don't need to change and that's it. (Meena, interview, n.d.) 
At the conclusion of our interview Meena offered her advice for other new immigrant children. She said,

Find someone who is facing the same challenges as you and it makes it a lot easier to go through those challenges with a friend rather than being alone. Keep on working hard you will find your way one day. Maybe this whole process broke your heart but one day you will achieve what you want to achieve. Never lose your roots. (Meena, interview, n.d.)

\section{Table 1}

Meena's Early Memories of School in Canada

\begin{tabular}{|l|l|l|}
\hline \multicolumn{1}{|c|}{ School's attitude } & Teachers' attitude & Peers' attitude \\
\hline not very understanding & thought I am not a good & make fun of me \\
student & not able to comprehend & made fun of my accent \\
\hline put a grade behind & my problems & make fun of me and the \\
\hline & not as flexible & way I dressed. \\
& & \\
\hline & underestimate me & \\
& &
\end{tabular}




\section{Table 2}

Meena's Experience Before and After Immigration

\begin{tabular}{|c|c|c|}
\hline Before Immigration & Just after immigration & At Present \\
\hline very sociable & scared & adapt to the schooling system \\
\hline good teachers & not comfortable & made friends \\
\hline made friends fast & isolated & $\begin{array}{l}\text { not ashamed of my identity } \\
\text { any more }\end{array}$ \\
\hline \multirow[t]{8}{*}{ long list of honour roll } & felt embarrassed & $\begin{array}{l}\text { able to share problems } \\
\text { concerns }\end{array}$ \\
\hline & lonely & $\begin{array}{l}\text { teacher also noticed my good } \\
\text { qualities }\end{array}$ \\
\hline & alone & able to answer back \\
\hline & lost appetite & \\
\hline & tried to change & $\begin{array}{l}\text { feel very worthwhile when got } \\
\text { my name on honour roll list }\end{array}$ \\
\hline & ashamed of my identity & $\begin{array}{l}\text { Canadian schools gave me } \\
\text { confidence }\end{array}$ \\
\hline & tried to hide & $\begin{array}{l}\text { focused on education goals } \\
\text { not social difficulties }\end{array}$ \\
\hline & left on my own & $\begin{array}{l}\text { I am what I am I don't need to } \\
\text { change and that's it. }\end{array}$ \\
\hline
\end{tabular}

I always thought I knew a lot about my daughter because I am her mother and thought nothing could be hidden from a mother. I am always there when she is in need. I always thought I was a perfect mother who brought her children to Canada and provided them with everything they wanted, both physically and emotionally. I never thought that my little girl was so alone when she came here. I never thought about how she coped with all these things and how deep her understanding is. I read so many articles on this issue, but never felt like I felt when my own daughter was in front of me with tears in her eyes telling me her journey of immigration. I think everyone should do such interviews on the issues related to their loved ones. I realize also that as Meena shared her stories with me, she made references to the times when she had shared these 
experiences with me at the times of their occurrences. I had almost forgotten them all. This made me realize how important it is to sit and listen to each other and how we sometimes ignore those close to us in our busy lives.

The pre-interview activity created the opportunity for Meena to recall and share the new school immigration experience with me. As I heard and felt Meena's stories I also felt compelled to re-focus my research question in my own research program. I now wish to pursue the question of, "How do immigrant children transform their old identity to a new identity in their new homelands?”

\section{Intercultural Communication Challenges for Chinese International Students}

Jun Deng, previously a college English teacher in China, is currently a doctoral student in TESL in the Department of Educational Psychology at the University of Alberta. Her research interests concern cultural difference and intercultural communication. With an increasing number of undergraduate and graduate students from China traveling overseas for further studies, Deng wants to learn how they cope with cultural difference and how they experience intercultural communication. In the following account, Deng writes about her interview with a male Chinese international graduate student at the University of Alberta.

My (Jun) participant, David (pseudonym), is a Chinese graduate student at the University of Alberta in his fourth year of a PhD program. We have known each other for about 4 years. He was formerly a university science teacher in China. He is friendly, generous, and easy-going. He has a large number of Chinese friends. He has regularly attended an English Bible study group on a weekly basis for the past 2 years so that he could practice English. His English is fluent, only having a slight accent. Because he has been living and studying in Canada for a number of years, I expected that he would have many stories to tell.

Two days before the interview, I emailed three pre-interview activities to David, so that he could choose and complete one to bring to the interview. I offered the following activies: Draw two pictures to show what life was/is like for you before and after coming to Canada; Make two schedules that show how a day, a week or a year is spent before and after coming to Canada; or Make a timeline of critical events that show how you have experienced cultural differences since you arrived in Canada.

When David came to the interview, I was surprised to learn that he had not completed any of the pre-interview activities. He explained that he had never done such activities before, and as a result, had no idea what exactly he was expected to do. Immediately, I developed an alternate pre-interview activity. I suggested that he think about the places where he was most likely to meet people from different cultural backgrounds, such as university or church. I asked him to list all of the people he frequently interacts with and to write down the key ideas that come to his mind. I handed him paper and pen, then sat back and waited. David began brainstorming immediately and wrote one and a half pages. Then he looked up and smiled saying, "Thank you for your reminder. It brings back a lot of memories." His brainstormed list included five subtopics: landlady, church, classmates, teachers, plagiarism, and relationships. Under each topic he wrote in short sentences about his experiences and feelings.

Because I had been caught by surprise by the way the interview meeting started, I forgot that the intention was to begin the interview by having the participant talk about the completed pre-interview activity. Thus, after David had written his brainstormed list I said that I had some 
prepared questions and asked if we could start with those. To my further surprise, David held his work in his hand and said with insistence, "Let's start with this. Let me tell you some stories about my landlady first” (interview, n.d.). (We spoke in Mandarin during the interview and afterwards I developed an English translation of the transcribed interview.)

Following the list he had written, David began by telling stories about his landlady. Despite receiving an expensive gift from David and his wife and his generous help around the house, she asked him to share the cost of gas for regularly taking a ride with her to school. She once invited him and his family for a camping trip and then asked him to split the expenses without mentioning this before the trip. On the same theme of gifts and being friendly as opposed to being friends, David expressed his surprise at how volunteers at his church endeavour to help strangers (new international students) move and settle in the city. The confusion about gifting has led David to be extremely cautious.

Now I ask first, always ask first. For instance, if I take a lift, I will ask whether I need to share the gas or not. When I receive an invitation from friends, any friends, the first thing for me to do is to make it clear whether we share the bill or not. (David, interview, n.d.)

He told about his difficulties and disappointments in building a good relationship with some professors and local students. Regarding fellow students he said that:

It is not easy to establish stable and deep friendship with classmates, for we always switch classmates....As international students, we have difficulty in some courses. I hoped to find someone to discuss over the difficulties,... I asked a female local student whether I could have her phone number, so that I could contact her if I had any questions. But she refused. She even felt that I had some bad intentions.... I had no partners to work with in a course, I felt rather frustrated. But in China, classmates are also good friends. You know. They are very helpful. (David, interview, n.d.)

Regarding experiences with professors he explained that:

I wished to have someone to work with, to discuss over the difficulties in study. But even some professors would not give their email address. Some were not patient in answering students' question. In China, you know, a professor is not just a course instructor, but also a role model, a caring "parent," treating a student as a "child." (David, interview, n.d.)

Even worse, David had a very unpleasant experience of plagiarism-a professor filed a report of plagiarism to the department because he forgot to cite sources for a term paper. He explained how contrary this was to the parent-like relationships professors have with students in China.

I forgot a writing assignment once. I was too busy. So, I spent one hour drafting the paper by combining some key sources and then submitted the paper in a rush....I did not take the assignment seriously. My thinking was simple. If the paper was not good, I could rewrite it. I never intended to steal others' ideas for publication....But the professor took it seriously. He failed me in the course. He even filed a report to the department....According to the policy, I had to withdraw from the program! It was unfair to me!...Another professor who knows about Chinese culture and Chinese students spoke for me and helped me out of the bad situation.... Some professors are nice, but some are not. 
What does "plagiarism" mean? If you express what the researchers say in your own words, like the local students do, it is not "plagiarism." In my case, I just had no time to rephrase the words and ideas. (David, interview, n.d.)

In our interview discussion, David concluded that for some professors, rules and norms take precedence over human relationships. He felt that some professors ignore the international student's cultural background. He also recognized his lack of knowledge about the western education system.

The interview with David included rich discussion as we worked together to clarify his interpretations of his experiences and identify important themes or patterns. The pre-interview activity of the brainstormed list helped David to remember a wide range of experiences to talk about. He was comfortable in taking the lead and knowing where he was going in telling me about the recalled experiences. As an interviewer, I was able to listen to his stories, follow his lead, and invite his further reflection or interpretation about each of the stories he told.

\section{Discussion}

Amjad and Deng both found that the pre-interview activities served as effective prompts or vehicles for their participants to recall and record specific events from their past experiences. When their participants, Meena and David, completed these activities they were free to focus on what was salient or meaningful for them with regards to the general topic or question. After completing his list of places and people, David said: "Thank you for your reminder. It brings back a lot of memories" (David, interview, n.d.). With their participants being able to take the lead in telling stories, comfortable and conversational interviews unfolded. As interviewers, Amjad and Deng were able to listen to stories without having to worry about the right questions to ask in order to prompt memories of the stories. Instead they could focus on expressing interest in the stories and inviting further interpretation or reflection from the participant as Deng did.

Being relieved of the pressure of worrying about the next question to ask, the interviewers were available to hear and be affected by the stories to which they were listening. Feeling genuinely heard, the participants could feel more invited to keep telling their stories. Meena had tears in her eyes as she told some of her stories. Amjad wrote: "I read so many articles on this issue, but never felt like I felt when my own daughter was in front of me with tears in her eyes telling me her journey of immigration” (A. Amjad, report, p. 14). When interviewers can be fully present to participants and the stories they are hearing, a genuine connection, compassion, or human solidarity is more possible. Only through such grasping of a participant's perspective is a fusion of horizons occurring. Amjad noted:

I realize also that as Meena shared her stories with me, she made references to the times when she had shared these experiences with me at the times of their occurrences. I had almost forgotten them all. This made me realize how important it is to sit and listen to each other and how we sometimes ignore those close to us in our busy lives. (Meena, personal communication, n.d.)

Just as multi-tasking parents can be too busy to be fully present as listeners, interviewers, too, can be busy worrying about whether they are getting what they need for their studies and about whether they are asking questions well. When pre-interview activities create a venue for participants to tell stories about their experiences in their own way, interviewers can be less busy and more available to hear and respond to the stories. 
Packer and Addison (1989) have emphasized the necessity of openness, humility, and good will in interpretive inquiry and in entering the hermeneutic circle in the right way. These attributes entail a willingness to learn what a topic is about for a participant rather than hoping to prove a point one has identified in advance. They also entail trusting an open process for learning what is meaningful or salient about the topic for the participant. The approach of using pre-interview activities can be a useful way of opening the interview process so that participants can identify and share meaningful experiences and be heard by the researcher when they do. When the experiences of interest are ones that have occurred over a long period of time, the pre-interview activities can be particularly helpful in enabling participants to retrieve their memories. The two accounts shared in this article highlight the potential of pre-interview activities for such research about participants’ past experiences. 


\section{References}

Brenner, M. (2006). Interviewing in educational research. In J.L. Green, G. Camilli, \& P.B. Elmore (Eds.), Handbook of complementary methods in educational research (pp. 357-370). Mahwah, NJ: Lawrence Erlbaum.

Ellis, J. (1998). Interpretive inquiry as a formal research process. In J. Ellis (Ed.) Teaching from understanding: Teacher as interpretive inquirer (pp.15-32). New York: Garland.

Ellis, J. (2006). Researching children's experience hermeneutically and holistically. The Alberta Journal of Educational Research, 52(3), 111-126.

Fetterman, D. (2010). Ethnography: Step-by-step (3rd ed.). Thousand Oaks, CA: Sage.

Guba, E. G., \& Lincoln, Y.S. (1994). Competing paradigms in qualitative research. In N. K. Denzin \& Y. S. Lincoln (Eds.), Handbook of qualitative research (pp. 105-117). Thousand Oaks, CA: Sage.

Packer, M. J., \& Addison, R. B. (1989a). Evaluating an interpretive account. In M. J. Packer \& R. B. Addison (Eds.), Entering the circle: Hermeneutic investigation in psychology (pp. 275-292). Albany, NY: SUNY Press.

Packer, M. J., \& Addison, R. B. (1989b). Overview. In M. J. Packer \& R. B. Addison (Eds.), Entering the circle: Hermeneutic investigation in psychology (pp. 1-12). Albany, NY: SUNY Press.

Sawler, J. (2005). The experience of youths with physical disabilities in sport and physical activity settings. Unpublished master's thesis. University of Alberta, Edmonton, AB.

Smith, D. G. (1991). Hermeneutic inquiry: The hermeneutic imagination and the pedagogic text. In E.C. Short (Ed.), Forms of curriculum inquiry (pp. 187-210). Albany: SUNY Press.

Smith, D. G. (2002). Hermeneutic scholar. In M. P. Woolfe \& C. R. Pryor (Eds.), The mission of the scholar: research and practice-A tribute to Nelson Haggerson (pp. 183-200). New York: Peter Lang. 